\title{
Updated S3 Guidelines - Diagnosis and Treatment of Colorectal Carcinoma: Relevance for Radiological Diagnosis and Intervention
}

\author{
Aktualisierte S3-Leitlinie zur Diagnostik und Therapie des \\ kolorektalen Karzinoms: Bedeutung für die radiologische \\ Diagnostik und Intervention
}

Authors

Thomas J. Vogl' , Philippe L. Pereira², Thomas Helmberger ${ }^{6}$, Andreas G. Schreyer ${ }^{3}$, Wolff Schmiegel ${ }^{4}$, Sebastian Fischer ${ }^{1}$, Christopher Herzog ${ }^{5}$

Affiliations

1 Institute for Diagnostic and Interventional Radiology, University Hospital Frankfurt, Germany

2 Radiology, Minimal Invasive Therapies and Nuclear Medicine, SLK-Kliniken, Heilbronn, Germany

3 Department of Diagnostic Radiology, University Hospital Regensburg, Regensburg, Germany

4 Department of Gastroenterology and Hepatology, University Hospital Bochum, Bochum, Germany

5 Radiology, München, Germany

6 Department of Diagnostic and Interventional Radiology, Neuroradiology and Nuclear Medicine, Munich, Germany

Key words

colorectal cancer, ablation procedures, staging, S3 guidelines, follow-up

received 09.07.2018

accepted 06.08.2018

Bibliography

DOI https://doi.org/10.1055/a-0721-1947

Published online: 24.9 .2018

Fortschr Röntgenstr 2019; 191: 298-310

(c) Georg Thieme Verlag KG, Stuttgart · New York

ISSN 1438-9029

Correspondence

Prof. Thomas J. Vogl

Institut für Diagnostische und Interventionelle Radiologie,

J.-W.-Goethe-Universität Frankfurt, Theodor-Stern Kai 7,

60596 Frankfurt, Germany

Tel.: ++ 49/69/63017277

Fax: $++49 / 69 / 63017258$

T.vogl@em.uni-frankfurt.de

\section{ABSTRACT}

The updated German S3 guidelines "Colorectal Carcinoma“ were created as part of the oncology program of the Association of the Scientific Medical Societies (AWMF), German Cancer Society and the German Cancer Aid under the auspices of the German Society for Digestive and Metabolic Disorders (DGVS) and they replace the previous guidelines from 2013. The main changes in the updated guidelines include the latest recommendations regarding endoscopy and adjuvant/neoadjuvant therapies as well as a complete restructuring of the section regarding therapeutic approach in metastases and in the palliative situation. The present manuscript discusses the importance of the current recommendations for radiological diagnosis and treatment and is intended to enhance the quality of patient information and patient care by widespread distribution.

\section{Key Points:}

- Radiological recommendations for treating patients with colorectal carcinoma are presented.

- The different possibilities of radiological imaging for diagnosis are documented in detail.

- Radiologists should be acquainted with the different possibilities of oncological intervention in patients with colorectal carcinoma.

\section{Citation Format}

- Vogl TJ, Pereira PL, Schreyer AG et al. Updated S3 Guidelines - Diagnosis and Treatment of Colorectal Carcinoma: Relevance for Radiological Diagnosis and Intervention. Fortschr Röntgenstr 2019; 191: 298-310

\section{ZUSAMMENFASSUNG}

Die aktualisierte deutsche S3-Leitlinie „Kolorektales Karzinom“ entstand im Rahmen des Leitlinienprogramms Onkologie der AWMF, Deutschen Krebsgesellschaft und Deutschen Krebshilfe unter Federführung der Deutschen Gesellschaft für Verdauungs- und Stoffwechselkrankheiten (DGVS) und ersetzt die bisherige Leitlinie aus dem Jahr 2013. Die wesentlichen Neuerungen der überarbeiteten Leitlinien umfassen neben aktualisierten Empfehlungen hinsichtlich Endoskopie und adjuvanter bzw. neoadjuvanter Therapien vor allem eine komplette Überarbeitung und Neustrukturierung des Abschnitts zum therapeutischen Vorgehen bei Metastasierung und in der palliativen Situation. Der vorliegende Artikel stellt die Bedeutung der aktuellen Verhaltensempfehlungen für die radiologische Diagnostik und Therapie dar und soll durch eine flächendeckendere Verbreitung der Qualitätssteigerung bei Patienteninformation und -versorgung dienen. 


\section{Introduction}

An increasing rate of colorectal cancer has been seen over the last 30 years in industrialized countries. Therefore, with 64000 new cases and approximately 26000 deaths per year, colorectal carcinoma is one of the most common malignant tumors in Germany. However, both numbers are slight lower compared to 2013 (76000 and 27000 , respectively). The lifetime incidence remains high (approx. $6 \%$ ). Men are affected slightly more often than women, primarily in rectal carcinoma with a gender ratio of 6:4.

As in many tumor entities, the prognosis depends on the disease stage and has an average 5-year survival rate of $40-60 \%$. As a result of the continuous further development of diagnostic methods and optimization of surgical, neoadjuvant and palliative treatment concepts, age-standardized mortality rates have decreased in the last 10 years by more than 20 percent.

This article discusses the relevant recommendations of the updated 2017 S3 guidelines for the radiological diagnosis and treatment of colorectal cancer with the main statements and corresponding literature.

\section{Method}

The guidelines were coordinated and planned under the auspices of the German Society for Digestive and Metabolic Disorders, which was supported by the oncology guidelines program of the Association of the Scientific Medical Societies. This program is based on the medical knowledge of the professional societies and the German Cancer Society, the consensus of medical experts, users and patients and the rules for guideline creation of the Association of the Scientific Medical Societies. The use of the rules of the Association of the Scientific Medical Societies should serve as the basis for the development of high-quality oncology guidelines. The method is explicitly described in the guidelines report.

The levels of evidence of the systematically researched data were assigned according to the system of the Oxford Centre for Evidence-based Medicine ( $\triangleright$ Table 1 ) from which grades of recommendation for clinical assessment were derived ( $\bullet$ Fig. 1 ).

A group of experts with a total of 53 elected representatives and plenum members from 14 German medical societies and 7 additional professional organizations and associations were involved in the revision of the guidelines. They met twice for consensus building and discussions. The strength of consensus was classified based on the approval rating of the plenum ( $\triangleright$ Table 2 ).

The long version of these guidelines was published in the German Journal of Gastroenterology and is published online on the homepages of the oncology guidelines program of the German Cancer Society (www.leitlinienprogramm-onkologie.de), the Association of the Scientific Medical Societies (www.awmf.org), the German Cancer Aid (www.krebshilfe.de) and the German Society for Digestive and Metabolic Disorders (www.dgvs.de). In addition to the long version, a short version, a guidelines report, and evidence reports are published here.
- Table 1 Levels of evidence according to Oxford.

\begin{tabular}{|c|c|}
\hline grade & type of study \\
\hline 1a & $\begin{array}{l}\text { systematic overview of randomized controlled studies } \\
\text { (RCT) }\end{array}$ \\
\hline $1 \mathrm{~b}$ & RCT (with narrow confidence interval) \\
\hline 1c & all-or-none principle \\
\hline $2 a$ & systematic overview of well-designed cohort studies \\
\hline $2 b$ & A well-designed cohort study or an RCT of lower quality \\
\hline 2c & outcome studies, ecological studies \\
\hline 3a & systematic overview of case control studies \\
\hline $3 b$ & one case control study \\
\hline 4 & $\begin{array}{l}\text { case series or cohort/case control studies of lower } \\
\text { quality }\end{array}$ \\
\hline 5 & $\begin{array}{l}\text { expert opinion without explicit evaluation of the } \\
\text { evidence or based on physiological models/laboratory } \\
\text { research }\end{array}$ \\
\hline
\end{tabular}

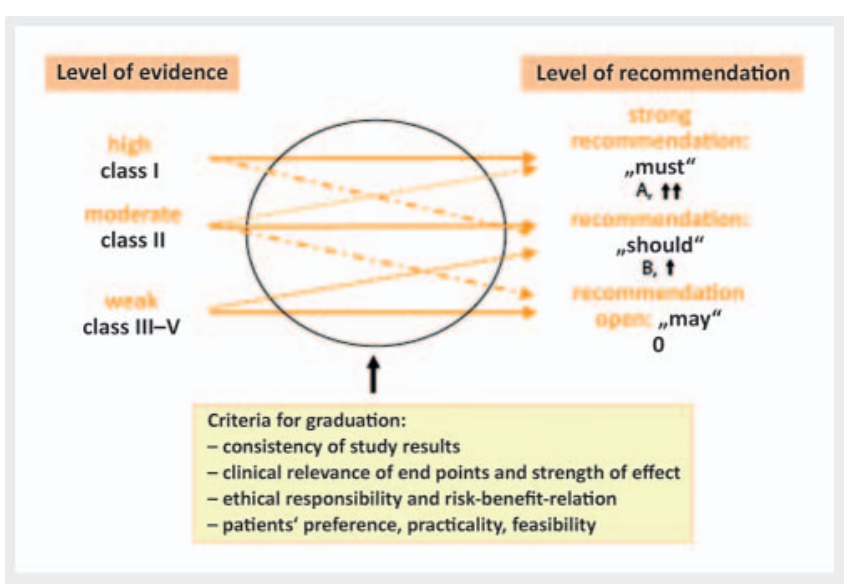

- Fig. 1 Classification of the grades of recommendation for clinical evaluation (according to recommendations of the Council of Europe 2001). The level of evidence usually determines the grade of recommendation. A deviation is possible with justification.

\section{Primary diagnosis}

Since it has the highest sensitivity and specificity in the early detection of colorectal neoplasias, colonoscopy continues to be the gold standard both in preventive care (screening) and in preoperative diagnosis. Since endoscopic methods also offer the advantage of therapeutic ablation, the adenoma-carcinoma sequence can be interrupted by endoscopic ablation and the formation of carcinomas and the colorectal cancer-based mortality can be consequently reduced [1]. Since synchronous tumors that can be missed by intraoperative assessment can be expected in up to $5 \%$ of colorectal carcinomas, colonoscopy of the entire colon should generally be performed [1 -4]. 
- Table 2 Classification of strength of consensus.

\begin{tabular}{|l|l|}
\hline $\begin{array}{l}\text { strength of } \\
\text { consensus }\end{array}$ & agreement in percent \\
\hline $\begin{array}{l}\text { strong } \\
\text { consensus }\end{array}$ & agreement of $>95 \%$ of participants \\
\hline consensus & agreement $>75-95 \%$ of participants \\
\hline $\begin{array}{l}\text { majority } \\
\text { agreement }\end{array}$ & agreement $>50-75 \%$ of participants \\
\hline \begin{tabular}{l} 
no consensus \\
\hline
\end{tabular} & agreement of less than $50 \%$ of participants \\
\hline
\end{tabular}

\section{CT or MR colonography}

\section{CONSENSUS-BASED STATEMENT}

CT colonography and MR colonography should not be used for colon cancer prevention/early detection in asymptomatic patients.

Level of evidence $3 b-$ De Novo

Grade of recommendation $B$

Vote in the plenum: Strong consensus

\section{Comment}

Even though the American Cancer Society has recommended $\mathrm{CT}$ colonography as a screening alternative in colorectal carcinoma since April 2008 [5], this is still not permitted in asymptomatic patients in Germany due to the radiation exposure and high availability of alternative endoscopic methods (Radiation Protection Ordinance $\S 80$ ). MR colonography is also currently not allowed as a screening method due to an insufficient number of studies $[6,7]$.

\section{CONSENSUS-BASED RECOMMENDATION}

In the case of incomplete colonoscopy due to a tumor causing stenosis, CT or MR colonography can additionally be performed on a preoperative basis.

Grade of recommendation 0

Level of evidence 4

Vote in the plenum: Strong consensus

In the case of incomplete colonoscopy for other reasons (e. g. adhesions), CT or MR colonography should be performed.

Grade of recommendation $B$

Level of evidence 4

Vote in the plenum: Strong consensus

\section{Comment}

However, if colonoscopy cannot be performed for technical reasons or due to patient refusal, both CT colonography [8, 9] and, to a lesser degree, MR colonography can be used as alternative radiological methods [10]. At least with respect to computed tomography (CT), this recommendation is in accordance with the joint guidelines of the European Society for Gastrointestinal Endoscopy and the European Society of Gastrointestinal and Abdominal Radiology from 2014 [11]. Two current meta-analyses show a sensitivity of $100 \%$ for the detection of carcinomas and $87.9 \%$ for the detection of adenomas $\geq 10 \mathrm{~mm}$. In the case of adenomas $>5 \mathrm{~mm}$, the sensitivity and specificity of CT colonography in screening candidates with a positive stool test decreased to $88 \%$ and $75 \%$, respectively [11]. In particular, flat polyps still often cannot be adequately detected [12-15].

In addition to a lack of expertise, suboptimal patient preparation and inadequate examination procedures limit the ability to obtain a valid interpretation of virtual colonography. Consequently, standardized training is needed in order to achieve knowledge of examination and evaluation techniques. Therefore, the European Society of Gastrointestinal and Abdominal Radiology (ESGAR) as well as the American College of Radiology recommend performing at least $50 \mathrm{CT}$ colonography examinations as part of training programs.

The primary goal of virtual colonography is thus to rule out additional lesions suspicious for malignancy so that it falls under the staging domains discussed in the following.

\section{Staging}

\section{Importance of individual imaging methods (except PET) for diagnosing distant metastases}

\section{CONSENSUS-BASED STATEMENT}

Abdominal ultrasound and conventional chest X-ray on 2 levels should be performed as basic examinations for the preoperative staging of colorectal cancer.

Multi-slice CT of the abdomen and pelvis should be performed in the case of an unclear finding or suspicion of distant metastases or infiltration of neighboring organs or surrounding structures and chest $\mathrm{CT}$ in the case of the suspicion of lung metastases.

Grade of recommendation: GCP

Vote in the plenum: Consensus

\section{Comment}

Pretherapeutic imaging is primarily used to assess distant metastases and lymphadenopathy. In $25 \%$ of patients with colon cancer and $18 \%$ of patients with rectal cancer, distant metastases are already present at the time of initial diagnosis. Metastases of colon cancer are restricted to one organ (M1a) in $13 \%$ of cases and to more than one organ or to the peritoneum (M1b) in $12 \%$ of cases. Liver metastases are seen in $19 \%$ of cases, lung metastases in $3 \%$, and peritoneal metastases in $9 \%$. Additional distant metastases in non-regional lymph nodes $(2 \%)$, the skin $(2 \%)$, the ovary $(1 \%)$, bone $(<1 \%)$, or other locations $(2 \%)$ are rare. Metastases of rectal cancer are restricted to one organ (M1a) in $12 \%$ of cases and to more than one organ or to the peritoneum (M1b) $6 \%$ of cases. Distant metastases in the liver are seen in $15 \%$ of cases 
and lung metastases in $4 \%$. Additional distant metastases are seen in the peritoneum in $3 \%$ of cases and in non-regional lymph nodes in $2 \%$ of cases. Distant metastases in the skin, bone, brain, ovary, or other locations are seen in fewer than $1 \%$ of cases. [Data from the Clinical Cancer Registry of the Surgical Clinic of the University of Erlangen-Nuremberg].

Primary conventional chest X-ray is sufficient for detecting lung metastases - concordant with simultaneous hepatic metastases in $45-70 \%$ of cases $[16,17]$. Compared to conventional imaging, chest CT shows higher sensitivity for the detection of pulmonary masses but significantly lower specificity. Based on the currently available studies, the clinical benefit of preoperative chest CT has not been sufficiently verified [17].

To diagnose liver metastases, primary abdominal ultrasound should be performed (sensitivity $63-86 \%$, specificity $98 \%$ ) [18$20]$. Contrast-enhanced ultrasound of the liver is almost equivalent (sensitivity $83-86 \%$, specificity $94-98 \%$ ) to CT and MRI but requires adequate quality standards (technical equipment and examiner experience) $[19,20]$. Therefore, abdominal CT examination (sensitivity $75-83 \%$, specificity $95-98 \%$ ) should be additionally performed in the case of suspicious ultrasound findings, insufficient ability to assess the liver on ultrasound or clinical suspicion of liver metastases [18, 21]. This allows assessment not only of the segmental allocation but also of the vascular supply and thus resectability of metastases. Alternatively, MRI of the liver whose diagnostic accuracy is superior to that of CT (sensitivity and specificity: MRI $80-88 \%$ and $93-97 \%$, CT $74-84 \%$, and $95-96 \%$ ) can also be performed [18, 21]. Since abdominal CT examination also allows assessment of the local tumor size, there is a tendency to perform primary abdominal CT examination instead of or in addition to ultrasound. However, in studies in patients with colon cancer, the routine use of preoperative CT resulted in a change in the further approach in only a few cases $[22,23]$.

\section{Value of CT and MRI in preoperative local staging}

\section{CONSENSUS-BASED RECOMMENDATION}

$\mathrm{CT}$ examination for preoperative staging can be used to differentiate between tumors that are limited to the intestinal wall and those that extend beyond it. However, the identification of nodal status is significantly more difficult. Multi-slice CT (MSCT) provides the best results.

Grade of recommendation: GCP

Vote in the plenum: Consensus

\section{Comment}

Preoperative ultrasound examination of the abdomen is insufficient for selection of the treatment algorithm. Multi-slice CT (MSCT) achieves high sensitivity (86\%) and specificity (78\%) for the evaluation of local tumor infiltration. However, local lymph node metastases are detected with a significantly lower sensitivity (70\%) [24]. There is currently insufficient data regarding the accuracy of MRI images for the local staging of colon cancer.

\section{Value of PET-CT in the primary diagnosis of colorectal cancer}

\section{CONSENSUS-BASED STATEMENT}

PET/PET-CT is not useful for staging in the initial diagnosis of colorectal cancer.

Level of evidence $2 b$ - De Novo

Vote in the plenum: Strong consensus

\section{Comment}

There are multiple comparative studies regarding the sensitivity of PET for distant metastases with overall heterogeneous study data $[24,25]$. Newer comparison studies using a multidetector spiral CT unit show no significant benefit of PET [26, 27].

Due to the low resolution of PET, the sensitivity for lymph node metastases is also low $(29-85 \%)$. Therefore, the method is not superior to other imaging modalities. Accordingly, the use of PET and $\mathrm{PET}-\mathrm{CT}$ resulted in a change in the therapeutic approach in only $2-27 \%$ of cases [26-29].

\section{CONSENSUS-BASED RECOMMENDATION}

PET-CT can be performed in patients with resectable liver metastases of colorectal carcinoma with the goal of avoiding an unnecessary laparotomy. Grade of recommendation 0 Level of evidence $2 b-$ De Novo Vote in the plenum: Consensus

\section{Comment}

Supplementary PET/PET-CT examination does not affect the disease-free or overall survival of colorectal cancer patients [30]. The study that served as the basis for the grade of recommendation $B$ for the implementation of PET/PET-CT prior to resection of colorectal liver metastases in the last update of the guidelines in 2008 has not yet been published as a manuscript [31]. Therefore, the grade of recommendation has been downgraded in the current guidelines.

The question as to whether supplementary PET-CT scan can prevent unnecessary laparotomies as a clinically relevant end point has not yet been definitively clarified by the currently available studies: However, one study including 150 patients with hepatic metastases of colorectal cancer was able to show that the percentage of unnecessary laparotomies was able to be lowered from $45 \%$ to $28 \%$ by performing a supplementary PET scan [32].

A supplementary PET/PET-CT scan prior to resection of liver metastases of colorectal cancer has no effect on the disease-free or overall survival of patients. The question as to whether a supplementary PET-CT examination can prevent unnecessary laparotomies as a clinically relevant end point has not yet been definitively clarified. The consensus recommendation is based on only one published study [32] albeit with methodological flaws. There was no significant difference in the survival rate in the PET 
arm but there was a significant reduction in the number of unnecessary laparotomies of $38 \%$ with a large confidence interval ( $95 \% \mathrm{Cl}, 4-60 \%, p=0.042$ ). The level of evidence of the study was downgraded by the consensus conference since the primary study end point indicated in the study plan deviated from that stated in the publication (original end point: rate of patients who were disease-free after 9 months). A further multicenter randomized study presented as an abstract at the ASCO annual meeting in 2011 also examined this issue [33]. The end point of this study was a change in patient management following PET imaging but was not achieved due to a lack of change.

\section{CONSENSUS-BASED RECOMMENDATION}

PET-CT should not be performed within 4 weeks after the administration of systemic chemotherapy or antibody therapy since the sensitivity is significantly reduced.

Grade of recommendation $A$

Level of evidence $2 b-$ De Novo

Vote in the plenum: Strong consensus

\section{Comment}

Due to an excessive number of false-negative PET findings within 4 weeks of systemic chemotherapy or antibody therapy, PET cannot be recommended within this time period [34, 35].

\section{Special diagnostic methods in the case of rectal cancer}

\section{CONSENSUS-BASED STATEMENT}

MRI should preferably be performed for the local staging of rectal cancer, while endoscopic ultrasound should be performed in suspected $\mathrm{T} 1$ carcinoma.

Grade of recommendation $B$

Level of evidence $2 b-$ De Novo

Vote in the plenum: Strong consensus

\section{CONSENSUS-BASED STATEMENT}

$\mathrm{CT}$ is not suitable for $\mathrm{T} 1$ carcinomas.

Level of evidence 3 - De Novo

Vote in the plenum: Strong consensus

\section{CONSENSUS-BASED STATEMENT}

The report should include a statement regarding the distance from mesorectal fascia.

Grade of recommendation: GCP

Vote in the plenum: Strong consensus

\section{Comment}

In light of the ability to visualize the mesorectal fascia in particular, MRI is currently preferred by many experts for the local staging of rectal cancer, with the exception of early carcinomas.

Local staging is particularly important for further treatment planning in the case of rectal cancer. While local ablation is sufficient for a low-risk T1 carcinoma, resection according to oncological criteria is necessary in high-risk T1 and T2 carcinomas.

Endoscopic ultrasound (EUS) has the highest accuracy in the diagnosis of $\mathrm{T} 1$ carcinomas and the differentiation of $\mathrm{T} 2$ and T3 carcinomas [36, 37]. MRI using an endorectal coil is a possible alternative to EUS but is associated with higher costs, is unpleasant for patients, and is established at only a few locations. CT is not suitable for this purpose.

Deeper rectal infiltrations with infiltration into the mesorectum (T3 and T4) required neoadjuvant therapy so that the distance from the mesorectal fascia has important prognostic significance [38]. If the mesorectal fascia has been infiltrated or if the tumor is within $1 \mathrm{~mm}$ of the fascia $(\mathrm{CRM}+)$, the local recurrence risk is significantly higher [38].

Since the mesorectal fascia can be effectively visualized on MRI in contrast to endoscopic ultrasound, MRI should be preferably used for the local staging of rectal cancer [6]. Spiral CT is a possible alternative [39]. The fascia cannot be visualized with endoscopic ultrasound.

\section{CONSENSUS-BASED STATEMENT}

The radial distance of the primary tumor (or affected lymph nodes) from the mesorectal fascia measured on thin-slice MRI (mrCRM) should not be used as a decision criterion for primary surgery outside of studies.

Grade of recommendation: GCP

Vote in the plenum: Consensus

\section{Comment}

The mrCRM determined by thin-slice MRI has a high prognostic significance for local control and disease-free survival and overall survival [31]. However, subgroup analyses of large randomized studies show that preoperative radiotherapy resulted in a further significant improvement in the local recurrence rate particularly in the case of pCRM-negative resection [40]. Therefore, the determination of the indication for neoadjuvant radiotherapy/radiochemotherapy versus primary surgery solely in relation to the selection criterion mrCRM currently requires additional qualityassured, prospective studies.

\section{CONSENSUS-BASED STATEMENT}

All imaging methods are subject to significant diagnostic uncertainty in the evaluation of lymph node status. Level of evidence $2 b-$ De Novo Vote in the plenum: Strong consensus 


\section{Comment}

The sensitivity (55-73\%) and specificity (74-78\%) of all methods in the evaluation of lymph nodes are currently unsatisfactory [37]. For this reason, the indication for neoadjuvant therapy should be made in a very conservative manner when it is based solely on the description of suspicious lymph nodes on pretherapeutic imaging. $>$ Table 3 shows an overview of preoperative staging.

\section{Treatment-relevant recommendations}

\section{Interdisciplinary tumor conference}

\section{CONSENSUS-BASED STATEMENT}

All patients with colorectal cancer should be presented in an interdisciplinary tumor conference after the completion of primary therapy (e.g. surgery, chemotherapy). Patients should be presented on a pretherapeutic basis in the following constellations:

- All cases of rectal cancer

- All cases of stage IV colon cancer

- Metachronous distant metastases

- Local recurrence

- Prior to every local ablation or locoregional measure, e. g. RFA/LITT/SIRT

Grade of recommendation: GCP

Vote in the plenum: Consensus

\section{Comment}

Due to the complexity of the treatment of colorectal carcinoma, the treatment concept should be discussed in an interdisciplinary tumor conference consisting of an experienced visceral surgeon, and at least one representative from the fields of gastroenterology, oncology, radiation therapy, radiology, and pathology.

The basic treatment goal in the case of colorectal carcinoma is radical surgical removal provided that a curative concept is possible.

In the case of distant metastases, primary or secondary resection of the metastases should be evaluated. Due to the intestinal blood flow through the portal vein and the right heart system, hepatic and pulmonary metastases are primarily seen here.

If $\mathrm{R} 0$ resection seems possible, primary surgery should be targeted. The 5-year survival rate after complete resection of colorectal liver metastases is between $25 \%$ and $40 \%$.

If a surgical approach is not possible, local ablation can also be used with a curative treatment intent.
- Table 3 Overview of preoperative staging.

\begin{tabular}{|l|l|l|}
\hline & colon carcinoma & rectal carcinoma \\
\hline chest X-ray & $\mathrm{x}$ & $\mathrm{x}$ \\
\hline complete colonoscopy & $\mathrm{x}$ & $\mathrm{x}$ \\
\hline abdominal ultrasound & $\begin{array}{l}\text { in the case of } \\
\text { unclear findings } \\
\text { or suspected } \\
\text { distant metasta- } \\
\text { ses or infiltration } \\
\text { of neighboring } \\
\text { organs or sur- } \\
\text { rounding struc- } \\
\text { tures }\end{array}$ \\
\hline abdominal CT & $\mathrm{x}$ & \\
\hline MRI (or CT) of the pelvis & $\mathrm{x}$ & $\mathrm{x}$ \\
\hline endoscopic ultrasound of & & \\
\hline the rectum & & \\
\hline rigid rectoscopy & & \\
\hline PET & & \\
\hline
\end{tabular}

\section{Local ablation methods}

\section{CONSENSUS-BASED RECOMMENDATION}

Local ablation methods can be used in the case of non-resectable metastases or if the general condition of the patient does not allow resection, particularly after previous liver metastasis resection.

Level of evidence $3 b$

Vote in the plenum: Strong consensus

\section{Comment}

Local ablation methods are used when surgical resection is not possible due to technical or patient-related factors. However, local ablation methods can also be performed in combination with surgical resection [ $41-43]$. The evidence regarding this topic is limited and sufficiently large, prospective, randomized studies are lacking. In primary resectable liver metastases that are also suitable for local ablation based on size and location, the indication for or against ablation should be determined in multidisciplinary tumor conferences. The best overall survival is achieved by a multimodal, possibly sequential treatment concept. The possibility of secondary resectability or performing local ablation measures should be examined by routine multidisciplinary tumor conferences on the basis of regular follow-up examinations. Radiofrequency ablation (RFA), microwave ablation (MWA), and high-conformal, hypofractionated radiation as in stereotactic radiation (SBRT) and [HDR] brachytherapy are to be considered to have comparable efficacy in the absence of randomized comparison studies. However, depending on the method, the indication varies as a function of location and vessel proximity. 


\section{Local ablation methods for treating liver metastases}

Thermoablation

There is sufficient data regarding the safety and efficacy of radiofrequency ablation (RFA) for the treatment of hepatic metastases supporting its use in patients who have non-resectable liver metastases, whose condition does not allow resection or who previously underwent liver resection [44]. RFA and MWA are to be considered largely equivalent here. However, MWA compared to RFA seems to be associated with a low local recurrence rate in the treatment of colorectal liver metastases close to large vessels [45].

The long-term survival of patients of up to 10 years after thermoablation is well documented in oligometastases to the liver [46]. Cohort studies and retrospective analyses show no difference between resection and thermoablation in metastases with a diameter of up to $3-4 \mathrm{~cm}$ with respect to survival [47 -49] so that thermoablation can be offered as an alternative to resection in the corresponding clinical constellation. However, a safety distance between the metastasis and induced coagulation of $5 \mathrm{~mm}$ should be maintained [50]. Multiple studies highlight the advantages of ablation with the possibility of repeating the intervention.

The combination of RFA (plus surgical) treatment and chemotherapy seems to result in a significant increase in the PFS as well as the overall survival [32].

Even if LITT is also an efficient and safe method for local ablation of inoperable liver metastases [51, 52], LITT and electroporation currently cannot be recommended for the treatment of liver metastases in colorectal cancer outside of clinical studies given the continued lack of prospective controlled studies.

\section{Additional locally effective interventions}

To date, the use of other local ablation methods has been primarily examined in case series and small cohort studies so that their oncological value has not yet been sufficiently validated [53, 54]. This includes methods with insufficient evidence such as stereotactic radiation (SBRT), brachytherapy, cryotherapy, and irreversible electroporation (IRE).

A 2-year survival rate between $32 \%$ and $83 \%$ for SBRT is specified in the literature $[55,56]$, and a median survival rate of up to 23.4 months for brachytherapy [57]. Studies including larger patient populations with a 5 -year survival rate or randomized studies compared to surgical resection or thermoablation for colorectal liver metastases are currently not available.

\section{Local ablation methods for treating lung metastases}

The resectability of lung metastases and local treatment with the option of ablation (RFA, MWA) or radiation therapy (SBRT) should be decided by a multidisciplinary tumor board. Therefore, depending on the technique, local control between $69.2 \%$ and $88.3 \%$ seems to be possible given the presence of a maximum of 3 lung metastases with a maximum size of $3 \mathrm{~cm}$ per lung [58, 59]. However, randomized studies are currently not available. There are also no randomized studies regarding SBRT of lung metastases with only small published case numbers with risks of radiation-induced pneumonitis and restriction of the functional lung volume.

\section{Locoregional methods}

Locoregional methods include selective intraarterial radiotherapy (SIRT) and intraarterial chemotherapy of the liver (HAI, TACE).

\section{Selective intraarterial radioembolization (SIRT)}

\section{CONSENSUS-BASED RECOMMENDATION}

SIRT can be used to treat disseminated liver metastases in colorectal cancer in patients for whom no other equivalent treatment option is possible.

Level of evidence $2 b$

Vote in the plenum: Strong consensus

\section{Comment}

In comparatively small randomized studies, the combination of SIRT with 5-FU was more effective than chemotherapy alone. Both in "chemorefractory" patients treated multiple times and in firstline therapy, the inclusion of SIRT compared to treatment solely with 5 -FU resulted in an improvement in response rate (10\% versus $0 \%$ for chemorefractory patients), TTP (4.5 vs. 2.1 months for chemorefractory patients or 18.6 versus 3.6 months, $p<0.0005$ in first-line therapy) and OS (29.4 vs. 12.8 months, $p=0.025$ in firstline therapy) [60, 61].

In an analysis of 3 randomized multicenter studies, the combination of SIRT and oxaliplatin/5-FU-based first-line chemotherapy showed a significant improvement in response rate (odds ratio 1.52, $p=0.001$ ) and potential resectability [62] but no advantage with respect to PFS and overall survival. The low effect on the overall survival can be partly explained by the high percentage of synchronous hepatic and extrahepatic metastases at the start of treatment [62].

\section{Hepatic intraarterial chemotherapy (HAI)}

A current European multicenter phase II study shows that resectability associated with a 4-year survival rate of $37.4 \%$ can be achieved in second-line therapy with high-dose intraarterial chemotherapy. However, consensus regarding a recommendation for the implementation of $\mathrm{HAl}$ in liver-dominant metastases at specialized centers could not be reached.

\section{Use of irinotecan-loaded microbeads}

A prospective randomized study in the palliative situation in patients with disease progression after second- and third-line chemotherapy showed better survival with a better quality of life after intraarterial application of irinotecan-loaded particles [63]. A further prospective randomized study reported better response rates with better progression-free survival using a combination of FOLFOX+/-bevacizumab with irinotecan-loaded particles compared to FOLFOX administration+/-bevacizumab [64]. 
Follow-up

\section{CONSENSUS-BASED RECOMMENDATION}

Regular follow-up in patients with colorectal carcinoma and early tumor stage (UICC I) is not recommended after R0 resection in light of the low recurrence rate and the favorable prognosis. Follow-up colonoscopy should be performed in accordance with section 3.8 .3 of the new $\mathrm{S3}$ guidelines. Grade of recommendation: GCP

\section{CONSENSUS-BASED STATEMENT}

Regular follow-up examinations are indicated after $\mathrm{R} 0$ resection of colorectal carcinomas of UICC stages II and III.

Grade of recommendation $A$

Level of evidence 1a

Vote in the plenum: Strong consensus

However, in the case of recurrence, these examinations should only be performed if therapeutic consequences are to be expected.

Grade of recommendation: GCP

Vote in the plenum: Strong consensus

\section{Comment}

The goal of follow-up is to detect a recurrence in a potentially curative stage. After curative therapy, there is an increased risk for local or locoregional recurrence (3-24\%), the occurrence of distant metastases (25\%), and a metachronous secondary tumor $(1.5-10 \%)$ for 5 years. The recurrence risk is increased particularly in advanced tumor stages $[38,65]$.

A prospective study showed that patients with a long-term survival of $86 \%$ in UICC stage I have a very good prognosis after curative resection. The recurrence rate here was $4 \%$ in UICC stage la and $13 \%$ in UICC stage Ib, while a recurrence rate of $2.9 \%$ in UICC stage la and a recurrence rate of only $5.6 \%$ for UICC stage Ib were determined in a large retrospective study. The primary location of recurrence is the rectum $(11 \%)[66,67]$.

Multiple meta-analyses showed heterogeneous study data regarding programmed follow-up in advanced colorectal cancer stages with a lower benefit tending to be achieved by regular follow-ups. The general efficacy of colorectal cancer follow-up correlates with a survival time that is only $1 \%$ longer on average [68].

Based on this and in light of the low recurrence rate, regular follow-up of R0-resected colorectal carcinomas in UICC stage I is not recommended.

If an increased recurrence rate is expected based on intraoperative or pathological findings, frequent follow-up colonoscopy examinations can be performed in the individual case.

In comparison, the recurrence rate in advanced colorectal cancer (UICC stages II + III) is increased [38, 69]. Regular followup examinations should be performed in this case. However, evidence-based statements regarding the type and frequency of follow-up examinations cannot be made due to a lack of studies [70]. More intensive follow-up did not yield a benefit compared to standard follow-up in the majority of randomized controlled studies [71, 72].

Only endoscopic ultrasound is recommended in the updated guidelines as the visual detection method for programmed follow-up. The methods specified in the following can be optionally performed.

\section{Value of diagnostic methods for follow-up}

\section{Ultrasound}

\section{CONSENSUS-BASED RECOMMENDATION}

Ultrasound is technically suitable for detecting liver metastases. Routine use has not been established based on the available data. The expert commission considers ultrasound to be the simplest and most cost-effective method and therefore recommends its use for diagnosing liver metastases.

Grade of recommendation A

Level of evidence 5

Vote in the plenum: Strong consensus

\section{CONSENSUS-BASED RECOMMENDATION}

EUS is suitable for detecting local recurrence in the case of rectal cancer, particularly in combination with EUS-guided biopsy. A recommendation regarding routine primary use in follow-up currently cannot be made.

Grade of recommendation $B$

Level of evidence $3 b$

Vote in the plenum: Strong consensus

\section{Comment}

In a controlled randomized study [73], the use of ultrasound (and also computed tomography) did not affect the survival and resection rates of patients undergoing follow-up. Only one metaanalysis of multiple randomized studies showed a significant survival advantage from using an imaging method to evaluate the liver [74]. Although a lower sensitivity of ultrasound compared to CT was seen in most studies, abdominal ultrasound is recommended as a cost-effective, fast, and widely available method for detecting liver metastases.

In the case of rectal cancer, follow-up with endoscopic ultrasound is useful in the diagnosis of locoregional recurrence after sphincter-preserving rectal resection if endoscopic ultrasound is combined with biopsy [75]. However, due to the invasiveness of biopsy, endoscopic ultrasound should only be used when the suspicion of recurrence has already been raised by another examination modality. 


\section{Chest X-ray}

\section{CONSENSUS-BASED RECOMMENDATION}

A chest X-ray can be performed annually in patients with stage II and III rectal cancer to the fifth year.

Grade of recommendation 0

Level of evidence $3 b$ - De Novo

Vote in the plenum: Consensus

\section{Comment}

The systematic literature research performed by the authors of the $\mathrm{S} 3$ guidelines regarding the significance of conventional chest X-ray showed that $0.8 \%$ to $7.0 \%$ of all colorectal cancer patients having undergone curative resection developed pulmonary metastases and that 3.4 to $29.4 \%$ of all cases of pulmonary recurrence were detected by chest $\mathrm{X}$-ray.

If a differentiation is made between colon and rectal carcinomas, the benefit of chest X-ray seems to be higher in rectal cancer in accordance with the more frequent rates of metastasis than in colon cancer [16]. The benefit for colon cancer is not definitive enough to be able to make a recommendation for routine use of chest X-ray in follow-up.

\section{Computed tomography}

\section{CONSENSUS-BASED RECOMMENDATION} \\ Computed tomography is technically suitable for detecting \\ liver metastases, local recurrence in the small pelvis, and \\ lung metastases. Current data argues against routine use of \\ computed tomography in follow-up. \\ Grade of recommendation $B$ \\ Level of evidence $1 b$ \\ Vote in the plenum: Strong consensus
}

\section{Comment}

In controlled randomized studies, the use of computed tomography did not affect the average survival of patients receiving follow-up. Early detection of hepatic metastases did not increase the number of curative liver resections $[72,76]$.

The ASCO guidelines published in 2005 recommended annual abdominal CT examinations for 3 years. A comparison of the value of ultrasound versus CT was not examined in the included studies. Newer meta-analyses also do not show a clear advantage of CT compared to ultrasound so that routine use in asymptomatic patients was not recommended in the current $\mathrm{S} 3$ guidelines [74].

\section{Contrast enema, virtual colonography and PET-CT/ MRI}

\section{CONSENSUS-BASED STATEMENT}

Contrast enema, virtual colonography and PET, PET-CT and PET-MRI are not useful for programmed follow-up.

Grade of recommendation $B$

Level of evidence 4 - De Novo

Vote in the plenum: Strong consensus

\section{Comment}

To date, there is no data regarding the use of contrast enemas and virtual colonography in the follow-up of colorectal cancer. Therefore, virtual colonography does not replace endoscopic ultrasound methods of follow-up.

Only a few studies address the use of PET imaging for the programmed follow-up of asymptomatic colorectal cancer patients.

In a prospective randomized study published in 2003 by Winawer et al., a control group examined in the follow-up with conventional chest X-ray and abdominal ultrasound and CT was compared to a study group additionally examined with PET imaging. With the same recurrence rate, recurrences were detected an average of 3.2 months earlier in the PET group resulting in a greater number of surgical procedures [77]. Also in other studies with supposed absence of recurrence, recurrences were diagnosed earlier with PET imaging [78, 79]. However, a statement regarding the effect on the average survival time could not be made in the studies.

In light of the insufficient data available and the surgical consequences resulting in some cases from false-positive PET findings, the use of PET imaging for follow-up examination without a suspicion of recurrence is not currently recommended [77].

\section{Summary}

The new S3 guidelines on colorectal carcinoma replace the previous guidelines from 2013 and include updated recommendations regarding endoscopic ultrasound and adjuvant/neoadjuvant therapy primarily with complete revision and restructuring of the section regarding the therapeutic approach for metastases and in the palliative situation. The guidelines relate to a number of areas in radiology.

The recommendations regarding the value of radiology methods in preoperative diagnosis remain unchanged. Therefore, the recommendation is still to use CT or MR colonography only in the case of suspicion of malignancy and when endoscopic ultrasound is not technically feasible.

The fact that neither CT colonography - due to unnecessary radiation exposure - nor MR colonography - due to insufficient data - can currently be recommended for screening examinations in asymptomatic patients also remains unchanged.

Percutaneous abdominal ultrasound remains the method of choice for the locoregional staging of colorectal cancer. Only in the case of an unclear or pathological abdominal ultrasound find- 
ing or suspicion of infiltration of neighboring organs or surrounding structures should abdominal CT be performed for further diagnostic workup.

Chest X-ray on two planes is sufficient for the primary diagnosis of lung metastases and chest CT should only be added in the case of clinical suspicion of pulmonary metastases. There is still insufficient data to be able to recommend unrestricted use of MRI imaging in the staging of colon cancer in the guidelines. However, MRI can be used to best determine the oncologically relevant infiltration depth in the direction of the mesorectal fascia so that the method should be used in the local staging of advanced rectal carcinomas ( $\geq$ stage $\mathrm{T} 2$ ).

PET is still not recommended for the primary staging of colorectal carcinoma. However, it can be used in the case of the presence of potentially resectable liver metastases to prevent unnecessary laparotomies. Therefore, the grade of recommendation for preoperative FDG-PET-CT remains 0 .

The recommendations regarding the use of radiology methods for follow-up have also not changed. Conventional chest X-ray can be performed postoperatively in patients with stage II and III rectal cancer in the first five years.

The use of computed tomography for detecting recurrence and metastases continues to be recommended only in the case of clinical suspicion or suspicious laboratory results and should not be performed as part of systematic follow-up. Contrast enema, virtual colonography and PET, PET-CT and PET-MRI are still not recommended for programmed follow-up.

The new guidelines include extensive additions primarily regarding the therapeutic use of local ablation methods and also locoregional methods for the first time. The grade of recommendation for local ablation methods was increased from $3 a$ to $3 b$ and can thus be used if non-resectable metastases are present or the general condition of the patient does not allow resection, particularly after previous liver metastasis resection. However, this recommendation relates secondarily and exclusively to the thermoablation methods RFA and MWA, while the use of LITT and electroporation outside of clinical studies is still not recommended. Alternative, non-thermal, local ablation methods such as cryotherapy, SBRT, and brachytherapy have been included in the guidelines for the first time but are not recommended due to insufficient validation. SIRT as a locoregional method was upgraded from degree of recommendation $2 a$ to $2 b$ and can thus now also be used outside of studies for the treatment of disseminated colorectal liver metastases for which there is no other equivalent treatment option. No recommendation was made regarding $\mathrm{HAl}$, TACE, and the locoregional application of irinotecan-loaded microbeads in liver-dominant metastases. This also relates to the local ablation of lung metastases via RFA, MWA, and SBRT. Nonetheless, all of these methods and indications have been included in the new guidelines for the first time.

\section{Conflict of Interest}

The authors declare that they have no conflict of interest.
Correction: Vogl T], Pereira PL, Schreyer AG et al. Updated S3 Guidelines - Diagnosis and Treatment of Colorectal Carcinoma: Relevance for Radiological Diagnosis and Intervention. Fortschr Röntgenstr 2018; doi: 10.1055/a-0721-1947

On 26.9.2018 Thomas Helmberger was added as the third author and the first name of the author Herzog was changed to Christopher.

\section{References}

[1] Zauber AG, Winawer SJ, O’Brien MJ et al. Colonoscopic polypectomy and long-term prevention of colorectal-cancer deaths. N Engl J Med 2012; 366: $687-696$

[2] Faivre J. Endoscopic monitoring after excision of colorectal cancer. J Chir (Paris) 1997; 134: $283-285$

[3] Chen CC, Yang SH, Lin JK et al. Is it reasonable to add preoperative serum level of CEA and CA19-9 to staging for colorectal cancer. J Surg Res 2005; 124: $169-174$

[4] Barillari P, Ramacciato G, De Angelis R et al. Effect of preoperative colonoscopy on the incidence of synchronous and metachronous neoplasms. Acta Chir Scand 1990; 156: 163 - 166

[5] Rogalla P, Janka R, Baum U et al. CT colography: guideline of the Gastrointestinal Diagnostics Team of the German Radiological Society regarding the indication and technical implementation of endoluminal colon diagnostics using computed tomography (known as virtual colonoscopy). Rofo 2008; 180: 466-469

[6] Purkayastha S, Tekkis PP, Athanasiou T et al. Magnetic resonance colonography versus colonoscopy as a diagnostic investigation for colorectal cancer: a meta-analysis. Clin Radiol 2005; 60: 980-989

[7] Hartmann D, Bassler B, Schilling D et al. Colorectal polyps: detection with dark-lumen MR colonography versus conventional colonoscopy. Radiology 2006; 238: 143 - 149

[8] Neri E, Giusti P, Battolla L et al. Colorectal cancer: role of CT colonography in preoperative evaluation after incomplete colonoscopy. Radiology 2002; 223: 615-619

[9] Javeri K, Williams TR, Bonnett JW. An overview of the method, application, and various findings of computed tomographic colonography in patients after incomplete colonoscopy. Curr Probl Diagn Radiol 2010; 39: $262-274$

[10] Hartmann D, Bassler B, Schilling D et al. Incomplete conventional colonoscopy: magnetic resonance colonography in the evaluation of the proximal colon. Endoscopy 2005; 37: 816-820

[11] Spada C, Stoker J, Alarcon O et al. Clinical indications for computed tomographic colonography: European Society of Gastrointestinal Endoscopy (ESGE) and European Society of Gastrointestinal and Abdominal Radiology (ESGAR) Guideline. Endoscopy 2014; 46: 897-915

[12] de Haan MC, van Gelder RE, Graser A et al. Diagnostic value of CT-colonography as compared to colonoscopy in an asymptomatic screening population: a meta-analysis. Eur Radiol 2011; 21: 1747-1763

[13] El-Maraghi RH, Kielar AZ. CT colonography versus optical colonoscopy for screening asymptomatic patients for colorectal cancer a patient, intervention, comparison, outcome (PICO) analysis. Acad Radiol 2009; 16: $564-571$

[14] Halligan S, Altman DG, Taylor SA et al. CT colonography in the detection of colorectal polyps and cancer: systematic review, meta-analysis, and proposed minimum data set for study level reporting. Radiology 2005 ; 237: $893-904$ 
[15] Pickhardt PJ, Choi JR, Hwang I et al. Computed tomographic virtual colonoscopy to screen for colorectal neoplasia in asymptomatic adults. N Engl J Med 2003; 349: 2191 - 2200

[16] Mitry E, Guiu B, Cosconea S et al. Epidemiology, management and prognosis of colorectal cancer with lung metastases: a 30-year population-based study. Gut 2010; 59: $1383-1388$

[17] Parnaby CN, Bailey W, Balasingam A et al. Pulmonary staging in colorectal cancer: a review. Colorectal Dis 2012; 14: 660-670

[18] Floriani I, Torri V, Rulli E et al. Performance of imaging modalities in diagnosis of liver metastases from colorectal cancer: a systematic review and meta-analysis. J Magn Reson Imaging 2010; 31: 19-31

[19] Quaia E, D’Onofrio M, Palumbo A et al. Comparison of contrastenhanced ultrasonography versus baseline ultrasound and contrastenhanced computed tomography in metastatic disease of the liver: diagnostic performance and confidence. Eur Radiol 2006; 16: 1599- 1609

[20] Rafaelsen SR, Jakobsen A. Contrast-enhanced ultrasound vs multidetector-computed tomography for detecting liver metastases in colorectal cancer: a prospective, blinded, patient-by-patient analysis. Colorectal Dis 2011; 13: 420-425

[21] Niekel MC, Bipat S, Stoker J. Diagnostic imaging of colorectal liver metastases with CT, MR imaging, FDG PET, and/or FDG PET/CT: a metaanalysis of prospective studies including patients who have not previously undergone treatment. Radiology 2010; 257: 674-684

[22] Barton JB, Langdale LA, Cummins JS et al. The utility of routine preoperative computed tomography scanning in the management of veterans with colon cancer. Am J Surg 2002; 183: 499-503

[23] McAndrew MR, Saba AK. Efficacy of routine preoperative computed tomography scans in colon cancer. Am Surg 1999; 65: 205-208

[24] Dighe S, Purkayastha S, Swift I et al. Diagnostic precision of CT in local staging of colon cancers: a meta-analysis. Clin Radiol 2010; 65: 708 719

[25] Abdel-Nabi H, Doerr RJ, Lamonica DM et al. Staging of primary colorectal carcinomas with fluorine-18 fluorodeoxyglucose whole-body PET: correlation with histopathologic and CT findings. Radiology 1998; 206: $755-760$

[26] Akiyoshi T, Oya M, Fujimoto Y et al. Comparison of preoperative wholebody positron emission tomography with MDCT in patients with primary colorectal cancer. Colorectal Dis 2009; 11: 464-469

[27] Furukawa $\mathrm{H}$, Ikuma $\mathrm{H}$, Seki $\mathrm{A}$ et al. Positron emission tomography scanning is not superior to whole body multidetector helical computed tomography in the preoperative staging of colorectal cancer. Gut 2006; 55: $1007-1011$

[28] Kantorová I, Lipská L, Bêlohlávek O et al. Routine (18)F-FDG PET preoperative staging of colorectal cancer: comparison with conventional staging and its impact on treatment decision making. J Nucl Med 2003; 44: $1784-1788$

[29] Paskeviciute B, Bölling T, Brinkmann M et al. Impact of (18)F-FDG-PET/ CT on staging and irradiation of patients with locally advanced rectal cancer. Strahlenther Onkol 2009; 185: 260-265

[30] Positronenemissionstomografie (PET und PET/CT) bei rezidivierendem kolorektalem Karzinom - Vorbericht (vorläufige Nutzerbewertung). 2011

[31] Taylor FG, Quirke P, Heald RJ et al. Preoperative magnetic resonance imaging assessment of circumferential resection margin predicts disease-free survival and local recurrence: 5 -year follow-up results of the MERCURY study. J Clin Oncol 2014; 32: 34-43

[32] Ruers TJ, Wiering B, van der Sijp JR et al. Improved selection of patients for hepatic surgery of colorectal liver metastases with (18)F-FDG PET: a randomized study. J Nucl Med 2009; 50: 1036-1041

[33] Moulton CA. An Ontario Clinical Oncology Group (OCOG) randomized controlled trial (RCT) assessing FDG PET/CT in resectable liver colorectal adenocarcinoma metastases (CAM). Clin Oncol 2011. abstr 3520
[34] Adie S, Yip C, Chu F et al. Resection of liver metastases from colorectal cancer: does preoperative chemotherapy affect the accuracy of PET in preoperative planning. ANZ J Surg 2009; 79: 358-361

[35] Lubezky N, Metser U, Geva R et al. The role and limitations of 18-fluoro2-deoxy-D-glucose positron emission tomography (FDG-PET) scan and computerized tomography $(\mathrm{CT})$ in restaging patients with hepatic colorectal metastases following neoadjuvant chemotherapy: comparison with operative and pathological findings. J Gastrointest Surg 2007; 11: $472-478$

[36] Bipat S, Glas AS, Slors FJ et al. Rectal cancer: local staging and assessment of lymph node involvement with endoluminal US, CT, and MR imaging-a meta-analysis. Radiology 2004; 232: 773 - 783

[37] Puli SR, Reddy JB, Bechtold ML et al. Accuracy of endoscopic ultrasound to diagnose nodal invasion by rectal cancers: a meta-analysis and systematic review. Ann Surg Oncol 2009; 16: 1255-1265

[38] Merkel S, Meyer T, Göhl J et al. Late locoregional recurrence in rectal carcinoma. Eur J Surg Oncol 2002; 28: 716-722

[39] Ahmetoğlu A, Cansu A, Baki D et al. MDCT with multiplanar reconstruction in the preoperative local staging of rectal tumor. Abdom Imaging 2011; 36: $31-37$

[40] van Gijn W, Marijnen CA, Nagtegaal ID et al. Preoperative radiotherapy combined with total mesorectal excision for resectable rectal cancer: 12-year follow-up of the multicentre, randomised controlled TME trial. Lancet Oncol 2011; 12: 575-582

[41] Agcaoglu O, Aliyev S, Karabulut K et al. Complementary use of resection and radiofrequency ablation for the treatment of colorectal liver metastases: an analysis of 395 patients. World J Surg 2013; 37: $1333-1339$

[42] Sasaki K, Margonis GA, Andreatos N et al. Combined resection and RFA in colorectal liver metastases: stratification of long-term outcomes. J Surg Res 2016; 206: 182-189

[43] van Amerongen MJ, van der Stok EP, Fütterer JJ et al. Short term and long term results of patients with colorectal liver metastases undergoing surgery with or without radiofrequency ablation. Eur J Surg Oncol 2016; 42: $523-530$

[44] NICE NI. Radiofrequency ablation for the treatment of colorectal metastases in the liver. 2011

[45] Correa-Gallego C, Fong Y, Gonen M et al. A retrospective comparison of microwave ablation vs. radiofrequency ablation for colorectal cancer hepatic metastases. Ann Surg Oncol 2014; 21: 4278-4283

[46] Van Tilborg AA, Meijerink MR, Sietses C et al. Long-term results of radiofrequency ablation for unresectable colorectal liver metastases: a potentially curative intervention. $\mathrm{Br}$ J Radiol 2011; 84: 556 - 565

[47] Gillams A, Goldberg N, Ahmed M et al. Thermal ablation of colorectal liver metastases: a position paper by an international panel of ablation experts, The Interventional Oncology Sans Frontières meeting 2013. Eur Radiol 2015: 25: $3438-3454$

[48] Otto G, Düber C, Hoppe-Lotichius M et al. Radiofrequency ablation as first-line treatment in patients with early colorectal liver metastases amenable to surgery. Ann Surg 2010; 251: 796-803

[49] Saxena A, Chua TC, Chu FC et al. Impact of treatment modality and number of lesions on recurrence and survival outcomes after treatment of colorectal cancer liver metastases. J Gastrointest Oncol 2014; 5: 46 56

[50] Wang DS, Davalos EA et al. Superselective transhepatic arterial chemoembolization for hepatucellular carcinoma in high risk patients as a bridge towards liver transplantation - Abstract No. 30. Journal of Vascular and Interventional Radiology 2012; 23: S16

[51] Christophi C, Nikfarjam M, Malcontenti-Wilson C et al. Long-term survival of patients with unresectable colorectal liver metastases treated by percutaneous interstitial laser thermotherapy. World J Surg 2004; 28: 987-994

[52] Wietzke-Braun P, Schindler C, Raddatz D et al. Quality of life and outcome of ultrasound-guided laser interstitial thermo-therapy for non- 
resectable liver metastases of colorectal cancer. Eur ] Gastroenterol Hepatol 2004; 16: $389-395$

[53] Solbiati L, Livraghi T, Goldberg SN et al. Percutaneous radio-frequency ablation of hepatic metastases from colorectal cancer: long-term results in 117 patients. Radiology 2001; 221: 159-166

[54] Vogl T], Straub R, Eichler K et al. Malignant liver tumors treated with MR imaging-guided laser-induced thermotherapy: experience with complications in 899 patients (2520 lesions). Radiology 2002; 225: 367 - 377

[55] Herfarth KK, Debus J, Wannenmacher M. Stereotactic radiation therapy of liver metastases: update of the initial phase-I/II trial. Front Radiat Ther Oncol 2004; 38: $100-105$

[56] van der Pool AE, Méndez Romero A, Wunderink W et al. Stereotactic body radiation therapy for colorectal liver metastases. Br J Surg 2010; 97: $377-382$

[57] Ricke J, Mohnike K, Pech M et al. Local response and impact on survival after local ablation of liver metastases from colorectal carcinoma by computed tomography-guided high-dose-rate brachytherapy. Int J Radiat Oncol Biol Phys 2010; 78: 479-485

[58] de Baère T, Aupérin A, Deschamps F et al. Radiofrequency ablation is a valid treatment option for lung metastases: experience in 566 patients with 1037 metastases. Ann Oncol 2015; 26: 987 - 991

[59] Vogl T], Eckert R, Naguib NN et al. Thermal Ablation of Colorectal Lung Metastases: Retrospective Comparison Among Laser-Induced Thermotherapy, Radiofrequency Ablation, and Microwave Ablation. Am J Roentgenol 2016; 207: 1340 - 1349

[60] Hendlisz A, Van den Eynde M, Peeters M et al. Phase III trial comparing protracted intravenous fluorouracil infusion alone or with yttrium-90 resin microspheres radioembolization for liver-limited metastatic colorectal cancer refractory to standard chemotherapy. J Clin Oncol 2010; 28: $3687-3694$

[61] Van Hazel G, Blackwell A, Anderson J et al. Randomised phase 2 trial of SIR-Spheres plus fluorouracil/leucovorin chemotherapy versus fluorouracil/leucovorin chemotherapy alone in advanced colorectal cancer. J Surg Oncol 2004; 88: 78-85

[62] BGP G, GA VH. REsect: Blinded assessment of amenability to potentially curative treatment of previously unresectable colorectal cancer liver metastases (CRC LM) after chemotherapy \pm RadioEmbolization (SIRT) in the randomized SIRFLOX trial. J Clin Oncol vol. 35: Abstract 3532

[63] Fiorentini G, Del Conte A, De Simone M et al. Complete response of colorectal liver metastases after intra-arterial chemotherapy. Tumori 2008; 94: 489-492

[64] Martin RC, Scoggins CR, Schreeder M et al. Randomized controlled trial of irinotecan drug-eluting beads with simultaneous FOLFOX and bevacizumab for patients with unresectable colorectal liver-limited metastasis. Cancer 2015; 121: 3649-3658
[65] Hermanek P, Wiebelt H, Riedl S et al. Long-term results of surgical therapy of colon cancer. Results of the Colorectal Cancer Study Group. Chirurg 1994; 65: $287-297$

[66] Körner H, Söreide K, Stokkeland PJ et al. Systematic follow-up after curative surgery for colorectal cancer in Norway: a population-based audit of effectiveness, costs, and compliance. J Gastrointest Surg 2005; 9: $320-328$

[67] Wichmann MW, Müller C, Hornung HM et al. Results of long-term follow-up after curative resection of Dukes A colorectal cancer. World J Surg 2002; 26: $732-736$

[68] Kievit J. Colorectal cancer follow-up: a reassessment of empirical evidence on effectiveness. Eur J Surg Oncol 2000; 26: 322 - 328

[69] Bülow S, Christensen IJ, Harling $\mathrm{H}$ et al. Recurrence and survival after mesorectal excision for rectal cancer. Br J Surg 2003; 90: 974- 980

[70] Berman JM, Cheung RJ, Weinberg DS. Surveillance after colorectal cancer resection. Lancet 2000; 355: 395 - 399

[71] Kjeldsen B], Kronborg O, Fenger C et al. A prospective randomized study of follow-up after radical surgery for colorectal cancer. British Journal of Surgery 1997; 84: 666-669

[72] Schoemaker D, Black R, Giles L et al. Yearly colonoscopy, liver CT, and chest radiography do not influence 5-year survival of colorectal cancer patients. Gastroenterology 1998; 114: 7-14

[73] Mäkelä JT, Laitinen SO, Kairaluoma MI. Five-year follow-up after radical surgery for colorectal cancer. Results of a prospective randomized trial. Arch Surg 1995; 130: 1062 -1067

[74] Jeffery GM, Hickey BE, Hider P. Follow-up strategies for patients treated for non-metastatic colorectal cancer. Cochrane Database Syst Rev 2002; 1: CD002200

[75] Hünerbein M, Totkas S, Moesta KT et al. The role of transrectal ultrasound-guided biopsy in the postoperative follow-up of patients with rectal cancer. Surgery 2001; 129: 164-169

[76] Pietra N, Sarli L, Costi R et al. Role of follow-up in management of local recurrences of colorectal cancer: a prospective, randomized study. Dis Colon Rectum 1998; 41: 1127-1133

[77] Winawer S, Fletcher R, Rex D et al. Colorectal cancer screening and surveillance: clinical guidelines and rationale-Update based on new evidence. Gastroenterology 2003; 124: 544 - 560

[78] Sobhani I, Tiret E, Lebtahi R et al. Early detection of recurrence by 18FDG-PET in the follow-up of patients with colorectal cancer. $\mathrm{Br}$ J Cancer 2008; 98: 875-880

[79] Selvaggi F, Cuocolo A, Sciaudone G et al. FGD-PET in the follow-up of recurrent colorectal cancer. Colorectal Dis 2003; 5: 496-500 